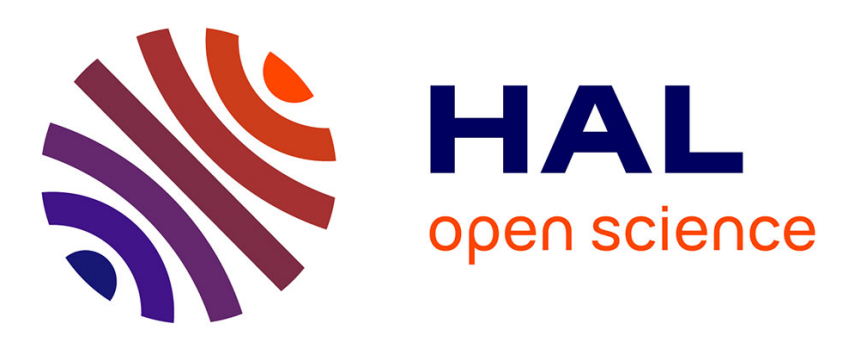

\title{
Impact of a shift in mean on the sea level rise: Application to the tide gauges in the Southern Netherlands
}

Melanie Becker, Mikhail Karpytchev, Manuel Davy, Koos Doekes

\section{- To cite this version:}

Melanie Becker, Mikhail Karpytchev, Manuel Davy, Koos Doekes. Impact of a shift in mean on the sea level rise: Application to the tide gauges in the Southern Netherlands. Continental Shelf Research, 2009, 29 (4), pp.741-749. 10.1016/j.csr.2008.12.005 . hal-01671909

\section{HAL Id: hal-01671909 \\ https://hal.science/hal-01671909}

Submitted on 11 Jan 2018

HAL is a multi-disciplinary open access archive for the deposit and dissemination of scientific research documents, whether they are published or not. The documents may come from teaching and research institutions in France or abroad, or from public or private research centers.
L'archive ouverte pluridisciplinaire HAL, est destinée au dépôt et à la diffusion de documents scientifiques de niveau recherche, publiés ou non, émanant des établissements d'enseignement et de recherche français ou étrangers, des laboratoires publics ou privés. 


\title{
Impact of a shift in mean on the sea level rise: Application to the tide gauges in the Southern Netherlands
}

\author{
M. Becker ${ }^{\mathrm{a}, *, 1}$, M. Karpytchev ${ }^{\mathrm{a}}$, M. Davy ${ }^{\mathrm{b}}$, K. Doekes $^{\mathrm{c}}$ \\ a Littoral Environnement et Sociétés (LIENSs), UMR 6250 CNRS-Université de La Rochelle, 2 Rue Olympe de Gouges, 17042 La Rochelle Cedex 01, France \\ ${ }^{\mathrm{b}}$ LAGIS, UMR CNRs 8146 and INRIA-FUTURS SequeL, BP 48, Cité Scientifique, Villeneuve d'Ascq, France \\ ${ }^{\mathrm{c}}$ Rijkswaterstaat-Waterdienst, next term Zuiderwagenplein 2, Postbus 17, 8200 AA Lelystad, The Netherlands
}

\section{A R T I C L E I N F O}

\section{Article history:}

Received 18 June 2008

Received in revised form

4 November 2008

Accepted 2 December 2008

Available online 24 December 2008

Keywords:

Time series analysis

Sea level rise

Southern Netherlands

\begin{abstract}
A B S T R A C T
The rates of sea level rise during 1940-2002 estimated in the Southern Netherlands at tide gauges of Vlissingen, IJmuiden, Maassluis and Hoek van Holland vary from 1.7 to $2.7 \mathrm{~mm} / \mathrm{yr}$ despite a relatively small distance $(<140 \mathrm{~km})$ between these stations. We have supposed that the observed inconsistency between the sea level trends could be due to an abrupt shift in the mean level of the tidal records provoked by some natural or anthropogenic processes. A shift detector based on the decomposition of the observations in empirical orthogonal functions and on the generalized likelihood ratio statistic has been constructed to evaluate the probability of the presence of a shift in the observed tidal records. A rapid change of mean of $25 \mathrm{~mm}$ at Hoek van Holland during the 1972-1973 period and of $17 \mathrm{~mm}$ at Vlissingen between 1973 and 1976 have been found to be statistically significant. The estimates of the sea level rise after correcting for shifts in the Vlissingen and Hoek van Holland tidal records are highly coherent and range between 1.9 and $2.1 \mathrm{~mm} / \mathrm{yr}$.
\end{abstract}

(c) 2009 Elsevier Ltd. All rights reserved.

\section{Introduction}

Tide gauge (TG) records have attracted much attention over the past decades in estimation of the sea level rise during the last two centuries (Douglas, 2001; Cazenave and Nerem, 2004; IPCC, 2007; Woodworth, 2006). Obtaining accurate estimates of long-term sea level trends is a complicated task because of two main reasons: first, many amount of physical processes influence the relative sea levels measured by TGs and, consequently, it is difficult to isolate climate-related sea level variations with high precision. Second, the long TG records (spanning at least $60 \mathrm{yr}$ in order to filter out inter-annual variabilities) are rather scarce and not uniformly distributed geographically (Douglas, 2001).

One obvious approach to increase the available set of the long TG records is to search for yet unknown observations in archives (Ekman, 1999). Another way consists in re-analysing available tidal records that have been systematically eliminated in previous studies because of their "anomalous" trends (Church et al., 2004; Holgate and Woodworth, 2004; Jevrejeva et al., 2006). If successful, the re-analysis would allow to correct the TG records

\footnotetext{
* Corresponding author. Tel.: +33546456818.

E-mail addresses: mbecker@univ-lr.fr, melanie.becker@legos.obs-mip.fr (M. Becker).

${ }^{1}$ Present address: Littoral Environnement et Sociétés (LIENSs), UMR 6250 CNRS-Université de La Rochelle, 2 Rue Olympe de Gouges, 17042 La Rochelle Cedex 01, France
}

for the contribution of processes not related to the secular sea level fluctuations induced by climate changes. The origin, time and space scales of these contaminating processes are extremely diverse and the re-analysis asks for detailed evaluation of all processes affecting sea level variations at a given TG. On the other hand, if the shape of the contaminating signal is assumed, one can apply statistical methods to detect the presence or absence of the supposed signal in the observed sea levels and to estimate its parameters. In this paper, we address the problem of detection of the contaminating processes that induce almost abrupt shifts in the mean level of monthly tidal records. A huge variety of natural and anthropogenic processes can provoke a rapid change in level in TG observations as, for example, instrumental errors in the acquisition system, datum errors or rapid land motion due to water pumping (Emery and Aubrey, 1991; Rodolfo and Siringan, 2006), earthquake (Fujii and Nakane, 1997; Seno, 2004; Day et al., 2005), river discharges (Gough and Robinson, 2000; Gough et al., 2005) or diverse urbanization effects (Gornitz, 1995).

Whether it is difficult to recognize a shift by a simple visual inspection depends on the shift's amplitude and the background noise in the tidal record. It seems impossible to distinguish by eye a shift from variations of white noise if the shift's amplitude is less than one standard deviation of the series under consideration (Kay, 1998). In fact, the standard deviation value yields an optimistic bound for the least amplitude of the shift that yet can be detected easily in tidal records as the serial correlation between sea levels makes the shift detection more difficult (von 
Storch and Zweirs, 1999). The typical values of the standard deviation in the longest ( $>60 \mathrm{yr}$ ) monthly TG records can be examined from the Permanent Service for Mean Sea Level (PSMSL Woodworth and Player, 2003) Web site (http://www.pol.ac.uk/ $\mathrm{psmsl} /$ ). The minimum value of standard deviation observed in these records is close to $70 \mathrm{~mm}$ (at TG stations of Auckland, Cascais and Honolulu).

How strong can be an impact of a $70 \mathrm{~mm}$ shift on the sea level rise estimate? The slope of regression line widely used for estimating the sea level trend is proportional to the shift amplitude (Appendix A). If, for example, a tidal record spanning $100 \mathrm{yr}$ has been offset at the midpoint by a $70 \mathrm{~mm}$ shift, its trend is increased (or decreased depending on the shift's sign) by $1.1 \mathrm{~mm} /$ yr. This perturbation of the trend is close to the average rate of sea level equalled to $1.7 \pm 0.5 \mathrm{~mm} / \mathrm{yr}$ (IPCC, 2007) during the 20th century. Hence, even a rather small shift can significantly bias the estimate of the sea level rise.

The necessity of developing and applying systematically the shift detection algorithms to the sea level analysis has been a major motivation of the present study. This study aims to analyse the discrepancy between the rates of sea level rise observed at four tidal stations in the Southern Netherlands: IJmuiden, Hoek van Holland, Maassluis and Vlissingen. Despite the closeness of these stations, the trends in their tidal records range from 1.7 to $2.7 \mathrm{~mm} / \mathrm{yr}$.

We have supposed that the cause of the observed discrepancy can be due to an abrupt change of the mean level in the tidal records. We applied the methods of statistical detection theory to decide on the presence of the shifts in the mean and to evaluate their positions and amplitudes.

The plan of the paper is as follows: first, we describe the data sets and their decomposition in the Empirical Orthogonal Functions (EOFs). Section 3 outlines the shift detection algorithms based on the generalized likelihood ratio (GLR). In Section 4, the GLR-based shift detector is applied to the Dutch tidal records. The results are summarized and discussed in the Sections 5-7.

\section{Data set and methods}

The Dutch TGs network is reputed for its quality and excellent datum control (Holgate and Woodworth, 2004) though these observations are not included in the Revised Local Reference data set of PSMSL (Woodworth and Player, 2003). All Dutch metric tidal data are referenced to NAP (Normaal Amsterdamsch Peil). Due to their quality and length they have been used in many studies of long term sea level variations (Langenberg et al., 1999; Woodworth, 1991; Holgate and Woodworth, 2004). We have chosen for the analysis four long term tidal stations in the Southern Netherlands: IJmuiden, Hoek van Holland, Maassluis and Vlissingen (Fig. 1). The monthly records have been downloaded from the PSMSL. We retain in each record a subset of the monthly SLH data from the year 1940 to 2002, in order to have a series of the minimum length $(60 \mathrm{yr})$ required for the long term sea level analysis (Douglas, 1997). These records are chosen because they are "ideal" for statistical analysis: they contain no gaps and no visible shifts during the period 1940-2002 (Fig. 2).

To estimate the linear trends shown in Fig. 1, and the confidence intervals we have applied the bootstrap method (Efron and Tibshirani, 1993). The trends obtained are $1.9 \pm 0.1 \mathrm{~mm} / \mathrm{yr}$ for IJmuiden, $2.7 \pm 0.1 \mathrm{~mm} / \mathrm{yr}$ for Hoek van Holland, $2.1 \pm 0.1 \mathrm{~mm} / \mathrm{yr}$ for Maassluis and $1.7 \pm 0.1 \mathrm{~mm} / \mathrm{yr}$ for Vlissingen. The sea level trends differ a lot: increasing from $1.7 \mathrm{~mm} / \mathrm{yr}$ at Vlissingen to $2.7 \mathrm{~mm} / \mathrm{yr}$ at Hoek van Holland. As the stations are rather close one to another, the observed spatial variability of the trends should be induced by some quite unknown local effects.

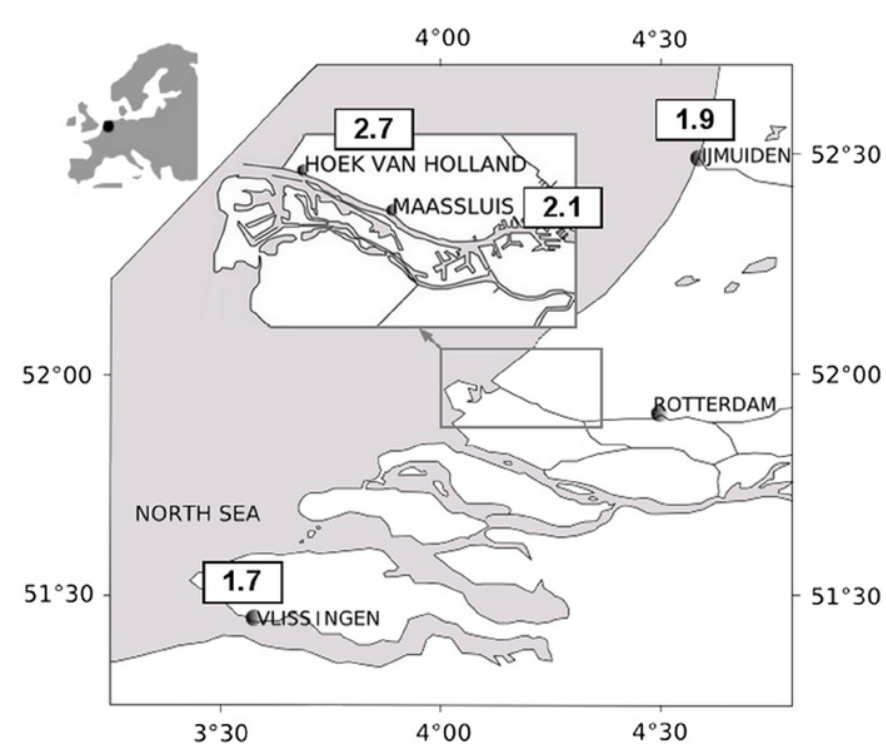

Fig. 1. Map of the Southern Netherlands with location of TG stations at IJmuiden, Hoek van Holland, Maassluis and Vlissingen. The numbers in black correspond to the sea level trend in mm/yr for the period 1940-2002.

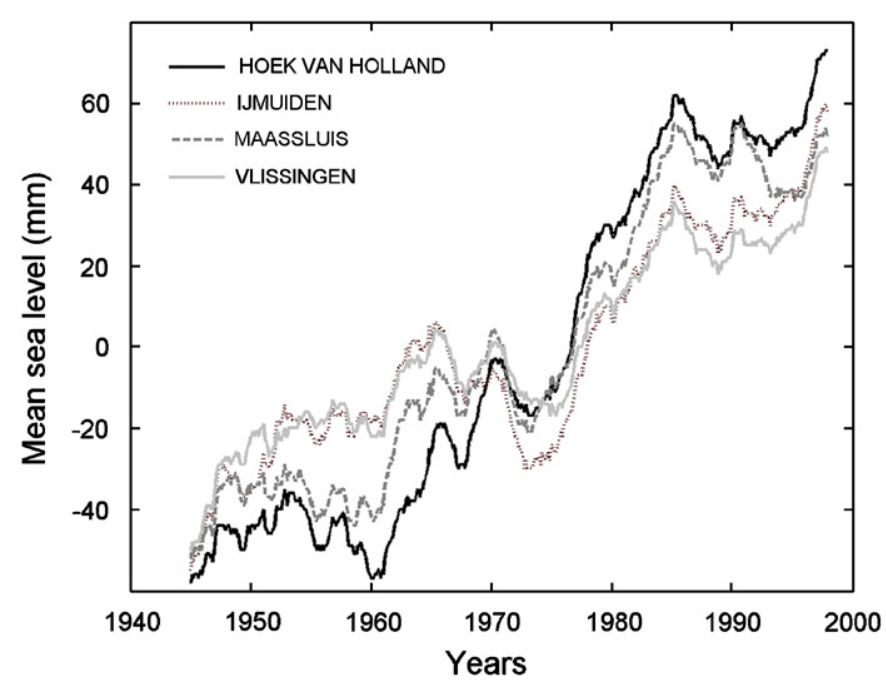

Fig. 2. Observed sea levels above NAP at IJmuiden, Hoek van Holland, Maassluis and Vlissingen smoothed by the 5-year moving average.

We have supposed that the observed discrepancy among the sea level trends is due to changes of hydrological regime or urbanization effects in the Southern Netherlands. An abrupt shift in mean of the tidal data occurs often as a response to the hydrological transformations (Gornitz, 2001). If not detected by the geodetic levelling, these shifts can significantly bias the estimates of sea level rise as illustrated above.

Two simple methods are routinely applied for searching for shifts in monthly SLH records. One technique is based on analysing the difference of consequent monthly values SLH: $\left\{\eta_{i+1}-\eta_{i}\right\}\left(\eta_{i}\right.$ is a mean SLH in a given month $\left.i\right)$. An abrupt shift in a tidal record results in a Dirac-like spell in the series of its derivatives. The method is applied separately for each site, but its efficiency is strongly limited owing to the large inter-annual variability of mean sea levels (Tawn et al., 1994). It is very difficult to detect small shifts using only the data from a single site. Another approach called "buddy checking" consists in subtracting a deseasonalized SLH record from one station from that of a 

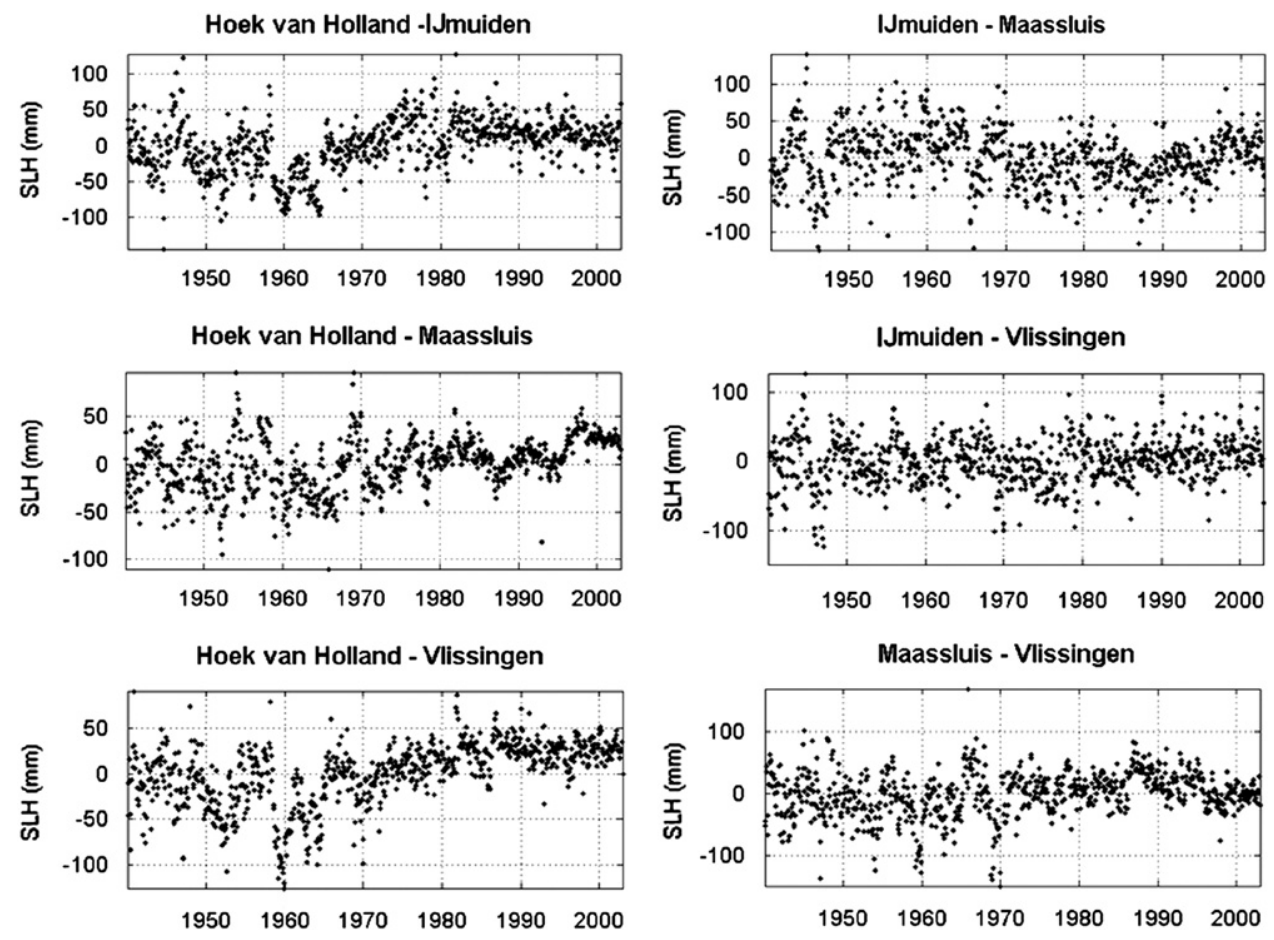

Fig. 3. The differences between the four deseasonalized SLH records (buddy checking).

neighbouring station. This method is efficient if the stations to be compared are so close that the regional steric and meteorological effects as well as any correlated residual variability will cancel out (Woodworth, 1987) from the difference between two records. We have applied this technique to the four long term tidal stations (Fig. 3). Fig. 3 displays various irregular spells in the differences between the four tidal records.

However, no reliable conclusion about a shift presence can be drawn from inspection of Fig. 3. This demonstrates the difficulty of detecting a datum simple shift by eyeball inspection of the buddy checking results.

To enhance the sea level variability due to local effects we will isolate the coherent global and regional variations by applying the EOF decomposition (Marcos et al., 2005; Preisendorfer, 1988; Woodworth et al., 1999). In this study, we do not modify our time series by eliminating long-term trends, which may be caused by long-term ocean or meteorological forcing or by vertical land movements, thus we preserve all statistical properties of the time series. The leading EOF (Fig. 4) has a homogeneous spatial pattern. It describes the coherent large-scale variations along the coast and accounts for $96 \%$ of the total variability. The second EOF (2\%) has IJmuiden and Maassluis regions out of phase with the Hoek van Holland and Vlissingen regions. The third EOF (1.1\%) shows the Vlissingen and Maassluis regions to be out of phase with the Hoek van Holland and IJmuiden regions. Finally, the fourth EOF (0.9\%) has the Hoek van Holland regions in phase with Maassluis regions and out of phase with others regions. The three last EOFs reflect the local sea variability.

For filtering each of the four station records we proceed as follows: we reconstruct a new series using the three first leading EOFs and the other three original records. The reconstruction is obtained from eigenvectors computed using the other original station records, which are assumed to not contain a shift. Also if there is a shift in one of the stations, the reconstruction for that station cannot reproduce it. As a consequence, the presence of a shift in the original record shows up as a slope in the differences between data and reconstruction (Marcos et al., 2005).

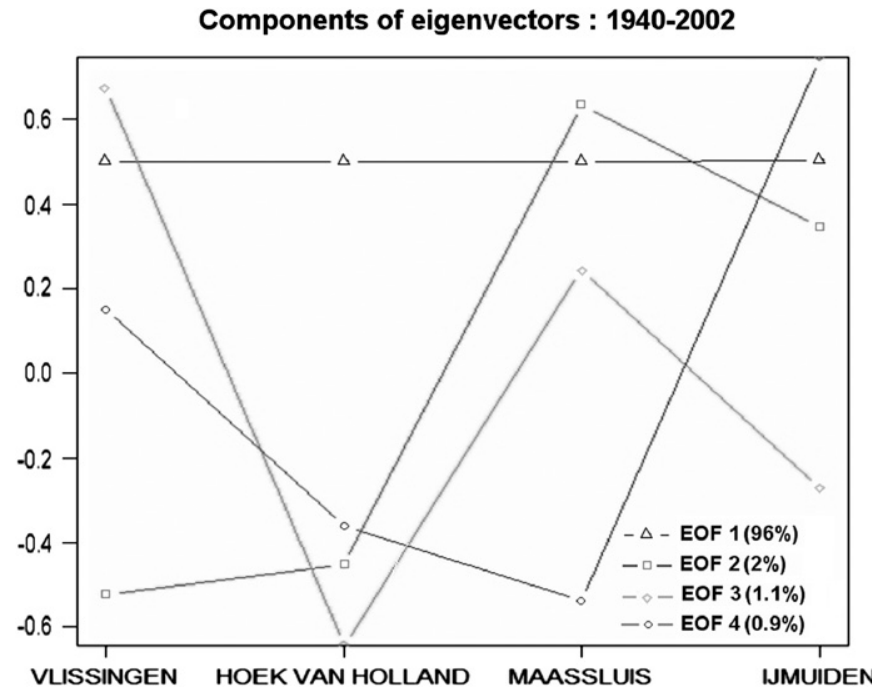

Fig. 4. Components of the eigenvectors computed for the four TG stations: IJmuiden, Hoek van Holland, Maassluis and Vlissingen.

For each station, the reconstruction was plotted and compared against the original observations (Fig. 5). We observe in Fig. 5 a difference of slope in the residual local SLH signal at the four stations between 1965 and 1980. This suggests the presence of a shift in one or several stations during this period. The sign of the shift in the residual SLH signal of Hoek van Holland is opposite to others. All these features give us a hint on the existence of a shift between 1965 and 1980 at the Hoek van Holland TG station.

\section{Detection of a shift in a tidal record: a GLR-based approach}

Let us consider a sequence of monthly sea level heights $\eta_{i}$ corresponding to times $\left(t_{i}\right)_{1 \leqslant i \leqslant M}$. Suppose we want to check 
EOF FILTER
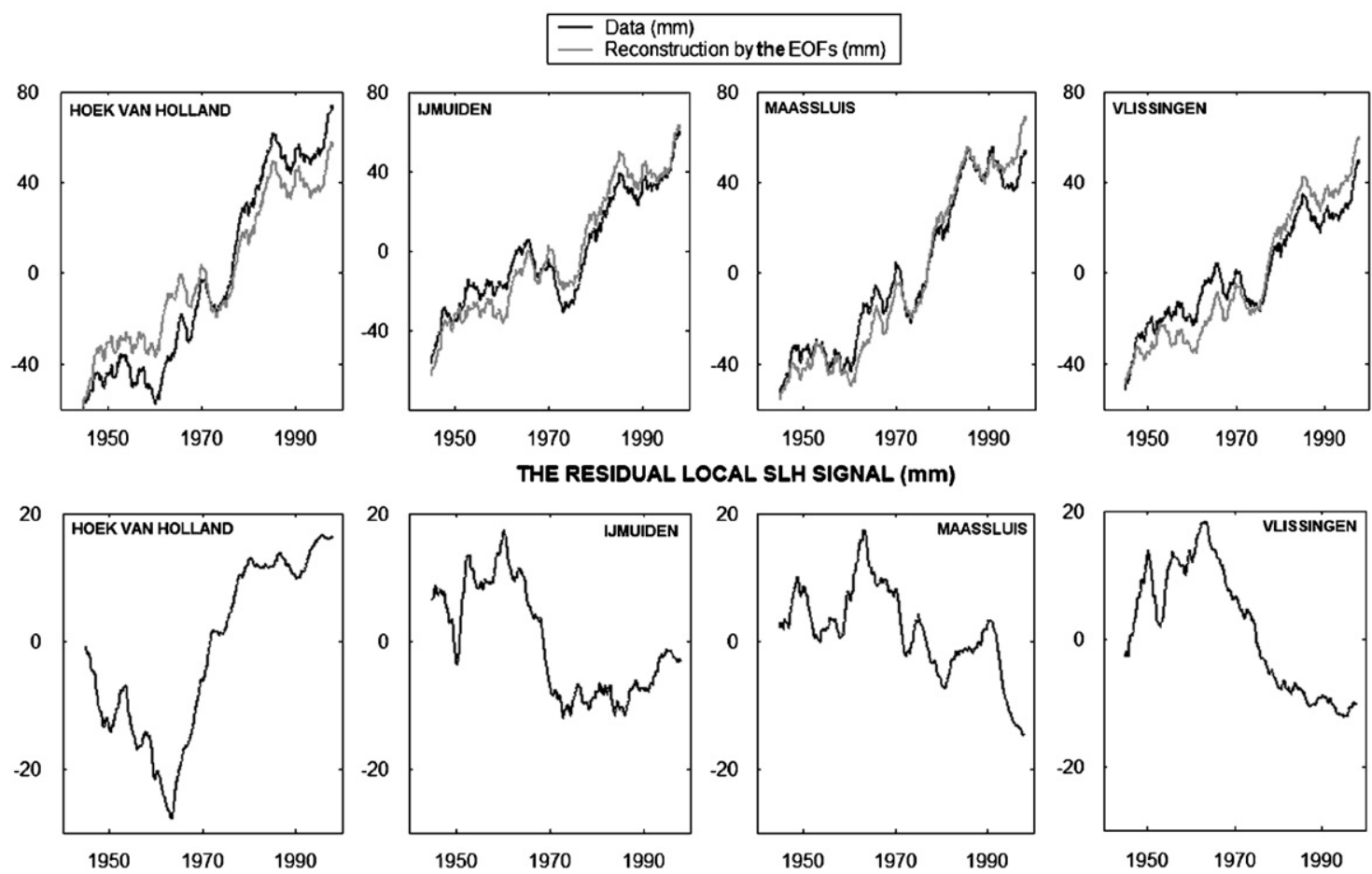

Fig. 5. The 5-year moving average of monthly SLH records filtered by the EOFs.

whether this sea level record has been offset at some unknown time $t_{s}$ by a sudden shift of unknown amplitude. In terms of statistical decision theory, this problem is equivalent to asking whether the subsample $\eta_{i}, i<t_{s}$, comes from a distribution with the mean $\mu_{1}$ different from the mean $\mu_{2}$ of the subsample $\eta_{i}, i>t_{s}$. This question can be answered by testing the null hypothesis $H_{0}$ : "the difference between the means of two subsamples is zero" against its alternative $H_{1}$ (Zweirs and von Storch, 1995):

$\left\{\begin{array}{l}H_{0}: \mu_{1}-\mu_{2}=0 \\ H_{1}: \mu_{1}-\mu_{2} \neq 0\end{array}\right.$

The means $\mu_{1}, \mu_{2}$ as well as the sea levels variances and the change time $t_{s}$ are supposed to be unknown. Comparison of means of two distributions is a classical topic of statistics (Brownlee, 1965) and a variety of parametric and nonparametric tests for means has been developed to decide whether or not $H_{0}$ can be rejected as e.g. the Student's t-test or the Mann-Whitney test (Berger and Labeyrie, 1987; Zweirs and von Storch, 1995; Rodionov, 2005).

In this study, we employ a model-adapted statistical decision rule based on evaluating the GLR. This approach is proved to be asymptotically optimal (Basseville and Nikiforov, 1993) and it has also the advantage of being easily generalized for searching a change of arbitrary shape. The basic idea of the GLR test is to compare the likelihood of observations under the hypothesis $H_{0}$ and under $H_{1}$. Assuming that the observed sea levels are drawn from a normal distribution with a mean $\mu_{i}$ and variance $\sigma^{2}$, the log-likelihood function of observations under $H_{0}$ reads

$L_{0}=\ln \left(L\left(\eta \mid H_{0}\right)\right) \propto-\sum_{i=1}^{i=M}\left(\eta_{i}-\hat{\mu_{0}}\right)^{2} / 2 \hat{\sigma}_{0}^{2}$

where $\hat{\mu}_{0}$ and $\hat{\sigma}_{0}$ are the Maximum Likelihood Estimates (MLEs) of mean and standard deviation. Under the hypothesis $H_{1}$, the log- likelihood function is given by:

$L_{1}=\ln \left(L\left(\eta \mid H_{1}\right)\right) \propto-\sum_{i=1}^{i=t_{s}}\left(\eta_{i}-\hat{\mu_{1}}\right)^{2} / 2{\hat{\sigma_{1}}}^{2}-\sum_{i=t_{s}+1}^{i=M}\left(\eta_{i}-\hat{\mu_{2}}\right)^{2} / 2{\hat{\sigma_{2}}}^{2}$

here $\hat{\mu}_{1}, \hat{\mu}_{2}$ and $\hat{\sigma}_{1}, \hat{\sigma_{2}}$ are the MLEs of the means and standard deviations in the subsamples of $\eta_{i}$ taken between $i=1, \ldots, t_{s}$ and $i=t_{s}+1, \ldots, M$, respectively.

The logarithm of the GLR corresponding to the hypothesis $H_{0}$ and $H_{1}$ is then

$\Lambda\left(t_{s}\right)=L_{1}-L_{0}$

The test statistic is based on the maximum value of the GLR, $\max _{t_{s}}(\Lambda)$, evaluated over the interval $t_{s}=1, \ldots, M$. Comparing it to a prescribed threshold $\Lambda_{0}$ provides the following decision rule:

$\left\{\begin{array}{l}\text { if } \max _{t_{s}}(\Lambda)<\Lambda_{0} \rightarrow \text { Accept } H_{0} \\ \text { if } \max _{t_{s}}(\Lambda)>\Lambda_{0} \rightarrow \text { Reject } H_{0}\end{array}\right.$

The change time is estimated as a value of $t_{s}$ maximizing $\Lambda$ (Basseville and Nikiforov, 1993)

$t_{s}^{e}=\operatorname{argmax}(\Lambda), \quad 1 \leqslant t_{s} \leqslant M$

The choice of the threshold value $\Lambda_{0}$ in Eq. (5) results from a trade off between two types of possible errors: (I) to reject $H_{0}$ when it is true (the "false alarms") and (II) to accept $H_{0}$ when it is false (the "missed shifts") (von Storch and Zweirs, 1999). The probability $\alpha$ of Type I error defines the significance level of statistical test. Denoting the probability of Type II error $\beta$, the power of test is defined as $p=1-\beta$. Lowering the threshold $\Lambda_{0}$ increases the number of false detections whereas increasing $\lambda_{0}$ produces more missed shifts (an ideal detector is characterized by $\alpha=0$ and $\beta=0$ ). 
In the following applications of the decision rule (Eq. (5)), the threshold $\Lambda_{0}$ is set to the upper $5 \%$ percentile of the test statistic $\max (\Lambda)$. The value of $5 \%$ percentile has been determined from Monte Carlo simulations of $\max (\Lambda)$ under hypothesis $H_{0}$ for several models of noise in tidal records which are detailed in the following section. Exceeding the 5\% significance level is not sufficient to declare the shift's presence to be statistically significant if the power of test is not evaluated.

Throughout the study, we have chosen a nominal value $p=$ 90\% (Brownlee, 1965), which should be exceeded in order to consider that a shift is detected.

\section{Application of the GLR detector to the tidal records}

In this section, the detector (Eq. (5)) is applied to the residual tidal records shown in Fig. 5. The GLRs, $\Lambda$, computed for four residual TG records are presented as a function of the change time $t_{s}$ in Fig. 6. The peaks of $\Lambda\left(t_{s}\right)$ are not sharp and we have introduced a change time interval defined as a set of instants $t_{i}$ for which the following inequality holds:

$\left|\Lambda\left(t_{i}\right)-\max (\Lambda)\right|<0.05 \max (\Lambda)$

The endpoints of the change time intervals together with the change time point $t_{s}^{e}$ estimated according to Eq. (6) and the amplitudes of the supposed shifts are summarized in Table 1.

Before discussing the possible origin and the consequences of the shifts indicated in Table 1 it is necessary to evaluate the statistical significance of the GLR peaks in Fig. 6. In other words, we should evaluate the probability that the GLR peaks in Fig. 6 are not due to fluctuations in the background noise of the sea level variations.

The analysis of statistical significance has been conducted by using a Monte Carlo generator simulating the background noise observed in the residual tidal records. For every tidal record, a total of $10^{4}$ time series of $60 \mathrm{yr}$ has been generated. These noise series satisfy hypothesis $H_{0}$ and the distribution of the maxima of their GLR has been analysed to estimate its upper 5\% percentile which serves as threshold $\Lambda_{0}$ in Eq. (5). The power of the GLR detector has then been estimated from the GLRs maxima in a similar way.

To create an ensemble of series with a shift, the mean level in every noisy series generated above has been offset according to the parameters of the supposed shift in Table 1 . The distribution of the GLR peaks obtained from these noise-plus-shift series has been used to evaluate the number of Monte Carlo samples falling above $\Lambda_{0}$. The obtained value is a Monte Carlo estimate of the detector power at the $5 \%$ significance level. If the observed GLR is higher than $\Lambda_{0}$ and, in addition, the detector power exceeds 0.90 then the shift listed in Table 1 is considered as statistically significant.

The reliability of the Monte Carlo approach depends obviously on the degree of similitude between the observed background noise and the simulated one. To get insight on the noise structure of the residual tidal records, Fig. 7 displays the estimates of their autocovariance functions (ACFs). The autocovariance between the sea levels is positive and exponentially decreasing for lags shorter than 11 months and fluctuates slowly between the confidence levels. The serial correlation indicates a long-range dependence among observations (coloured noise) that is typical for geophysical time series in general (Hurst, 1957; Mandelbrot and Van Ness, 1968) and tidal records in particular (Barbosa et al., 2006). To take it into account we have used two coloured noise models: one based on the auto-regressive model $\operatorname{AR}(1)$ and another generating the noise from the autocovariance matrix of observations by the Cholesky decomposition.

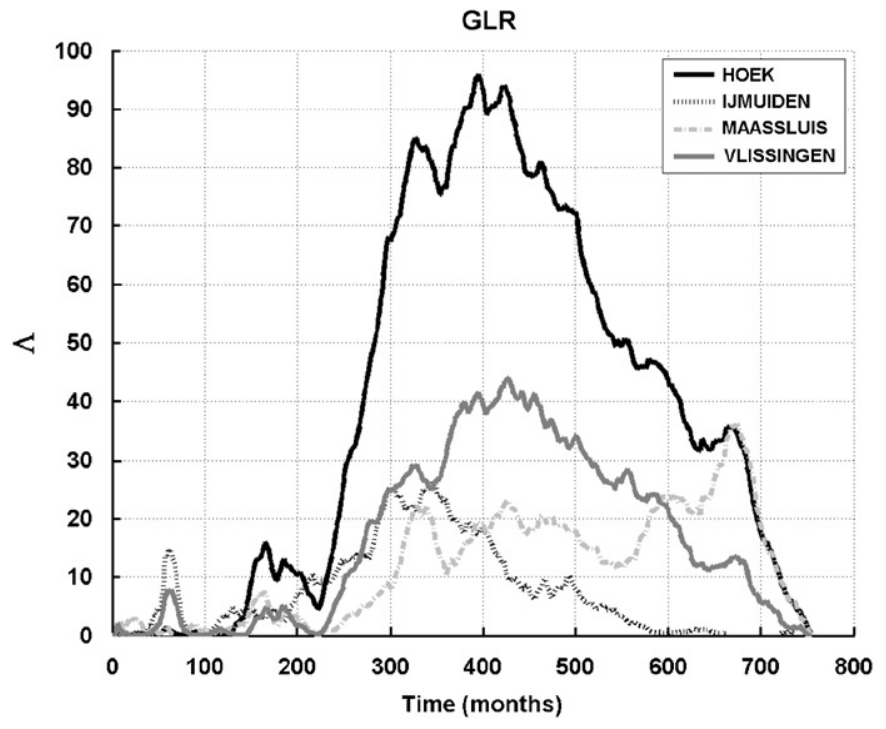

Fig. 6. The value of generalized likelihood ratio as a function of change time $t_{s}$ obtained from the residual tidal records (January $1940=$ month 1 ).

\section{Table 1}

The standard deviation, $\sigma$, maximum of GLR and the parameters of the derived shifts for four residual records.

\begin{tabular}{llllll}
\hline $\begin{array}{l}\text { Signal } \\
\text { filtered by } \\
\text { EOFs }\end{array}$ & $\sigma$ & $\Lambda$ max & $\begin{array}{l}\text { Change time } \\
\text { interval (5\%) }\end{array}$ & $\begin{array}{l}t_{0}^{e} \\
\text { (months) }\end{array}$ & $\begin{array}{l}\text { Amplitude } \\
\text { of shift }\end{array}$ \\
\hline IJmuiden & 27.4 & 26 & {$[1965-1968]$} & 346 & $-0.5 \sigma$ \\
Hoek v.H. & 24.8 & 95 & {$[1972-1973]$} & 395 & $1 \sigma$ \\
Maassluis & 27.4 & 36 & {$[1995-1996]$} & 674 & $-1 \sigma$ \\
Vlissingen & 24.9 & 44 & {$[1973-1976]$} & 428 & $-0.7 \sigma$ \\
\hline
\end{tabular}

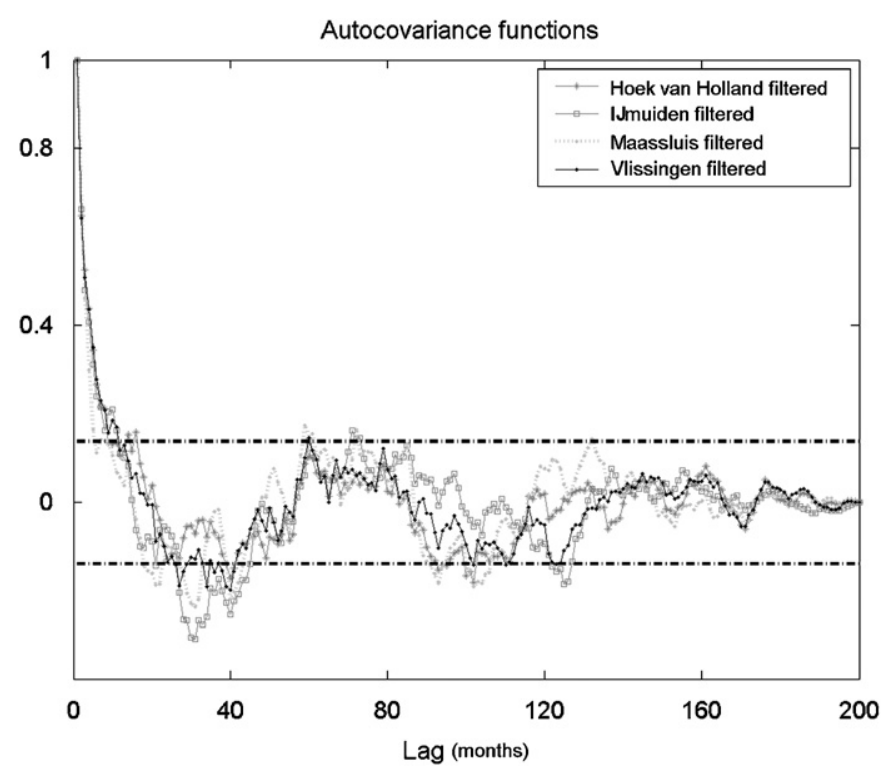

Fig. 7. ACFs of monthly SLH records filtered by the EOFs. The band delimited by the two horizontal lines indicates the $95 \%$ confidence interval.

The $\mathrm{AR}(1)$ noise is generated by the first-order auto-regressive process:

$\eta_{t+1}=\alpha \eta_{t}+\beta \varepsilon_{t}$ 
where $\eta_{t}$ is simulated sea level at instant $t, \alpha, \beta$ are parameters adjusted to produce the same lag- 1 autocorrelation and variance as observations (von Storch and Zweirs, 1999), and $\varepsilon_{t}$ is a white noise process.

The second model of the background noise is constructed by using the factorisation of auto-covariance matrix of observations, $\Sigma$, by the Cholesky decomposition:

$\Sigma=L L^{\mathrm{T}}$

The lower triangular matrix $L$ converted with a normally distributed random vector $\mathbf{x}$ produces another random vector $\mathbf{y}$ having the same ACF as that of the observed tidal records:

$\mathbf{y}=L \mathbf{x}$

Note, that here "the same" is mentioned in the statistical sense: the mean of the ACFs corresponding to the ensemble of $\mathbf{y}$ converges to the ACFs of observations.

In addition to the two coloured noise models, we have also calculated the threshold and the power of the detector for the case of tidal records corrupted by a pure white noise process in order to highlight the impact of the long-range dependence on the detectability of a shift.

The lines in Fig. 8 are the threshold values $\Lambda_{0}$ corresponding to the $5 \%$ significance level in the three noise models described above. If the sea level records were corrupted by white noise, the hypothesis $H_{0}$ should be rejected for all four tidal records. Taking into account the serial correlation between sea levels increases significantly the threshold but the AR(1) noise model rejects $H_{0}$ for all tidal records.

The noise model based on the Cholesky decomposition simulates the time series with ACFs much closer to the ACF of observed sea levels. The thresholds produced by this "realistic" noise model are systematically higher than that of the $\operatorname{AR}(1)$ process although the difference between the thresholds of two coloured models does not vary a lot for Maassluis sea levels. As the GLR of the IJmuiden record does not exceed the realistic noise threshold, we conclude that there is no statistical evidence to consider the mean level at IJmuiden to be perturbed by a shift.

Now, we will check whether the detector power attains $90 \%$ at the $5 \%$ significance level in the tidal records from Hoek van Holland, Maassluis and Vlissingen. A practical way to do it is to plot the power of the GLR test, $p$, as a function of the significance level $\alpha$. The resulting curve is termed receiver operating characteristics (ROC) in signal detection theory (Kay, 1998) where, by historical reasons, the detector power is often named as hit rate and the significance level as probability of false alarms. The ROCs for the three tidal records are displayed in Fig. 9. Every curve corresponds to one of three background noise models employed above in Monte Carlo simulations. With an ROC plot, assessing the performance of any detector is easy by comparing the corresponding curve to one of two limiting cases: (1) the bisector line which is the ROC of a "flipping coin" detector with the probability $50 \%$ of both false alarms and of correct detections and (2) an ROC of a perfect detector coinciding with the left and upper side of the square, for the white noise in Fig. 9. In this sense, the GRL-based detector (Eq. (5)) is perfect to recognize every shift from Table 1 when the tidal record is corrupted by white noise only. The serial correlation between observations causes the ROC of the detector (Eq. (5)) to deviate from the perfect ROC. Nevertheless, this deviation is insignificant for the observations from Vlissingen and Hoek van Holland: the power of the GLR test attains for these two records 93\% and 97\%, respectively. It means that the shift of $25 \mathrm{~mm}$ is sufficiently high to be recognised by the GLR detector (Eq. (5)) in the background noise at Hoek van Holland. A similar conclusion can be given for the $17 \mathrm{~mm}$ shift in the Vlissingen tidal record. Consequently, we conclude that the shifts in the mean of the tidal records of Hoek van Holland and Vlissingen are statistically significant. For Maassluis, the power of the GLR test attains only $88 \%$. This result cannot be considered as statistically significant and requires an additional investigation. Other values
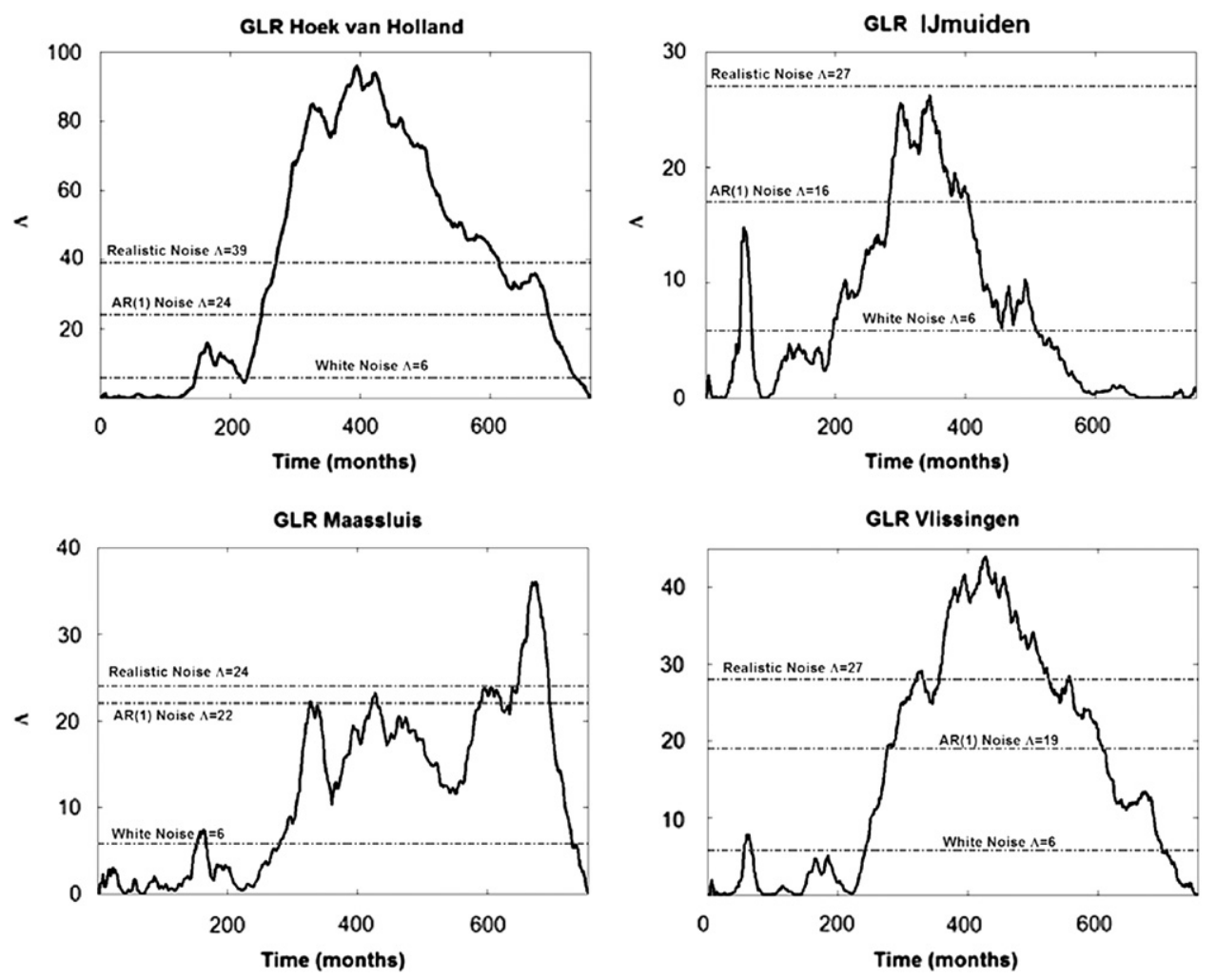

Fig. 8. The Generalized Likelihood Ratio amplitudes compared to the thresholds corresponding to 3 noise models. 

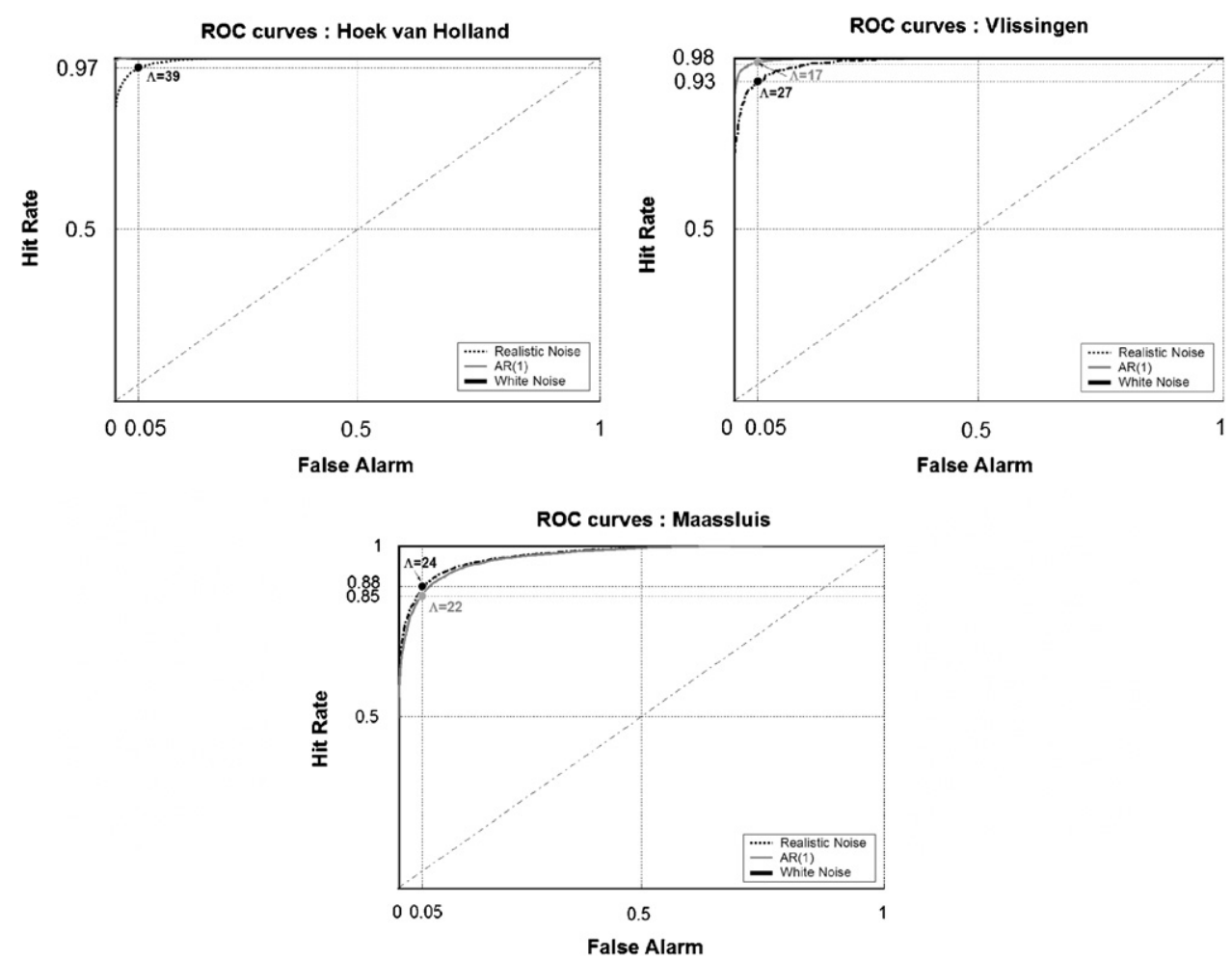

Fig. 9. Receiver operating characteristics $(\mathrm{ROC})$ for the three residual tidal records.

can be chosen both as the significance level and as the threshold of the power of the test. This choice is a subjective part of the decision theory based on the objective statistical considerations (Papoulis, 1991). Consequently, declaring the shift detection with $p=91 \%$ is obviously less reliable than doing with $p=99 \%$ although the threshold $p=90 \%$ is exceeded in only two cases.

\section{Possible sources of detected shifts}

We have searched in the available documentation for the processes which might have provoked a shift in tidal records at Hoek van Holland and Vlissingen. The processes responsible for the abrupt sea level rise of $25 \mathrm{~mm}$ at the Hoek van Holland TG around 1973 are likely to be anthropogenic. In this period, Rotterdam's harbour territory has been enlarged by constructing the Europoort complex along the mouth of the Nieuwe Waterweg, and by building up the extension of the Maasvlakte harbour close to the TG of Hoek van Holland (Hollebrandse, 2005). The Europoort lies just opposite the Hoek van Holland, at the entrance of the Nieuwe Waterweg Canal, a distributary of the Rhine. Its construction was begun in 1958. Moreover, in the 1970s the port was extended into the sea at the south side of the mouth of the Nieuwe Waterweg by completion of the Maasvlakte, by reclaiming land from the North Sea through dykes and sand suppletion. Over the years, the port was further developed seaward by building new docks and harbour-basins. A problem related to the industrial activity in the port of Rotterdam is the increased salt water intrusion. Deeper entrance channels and harbours have caused the salt water intrusion about $35 \mathrm{~km}$ further upstream during the last $60 \mathrm{yr}$ (Jelgersma, 1992).

It seems likely, however, that in the direct vicinity of Hoek van Holland TG abruptly dropped in the early 1970s, as a result of the extension of the northern pier. This is suggested by the annual average salinity measured along the beach just north of the northern pier (Fig. 10, http://www.waterstat.nl), which shows a

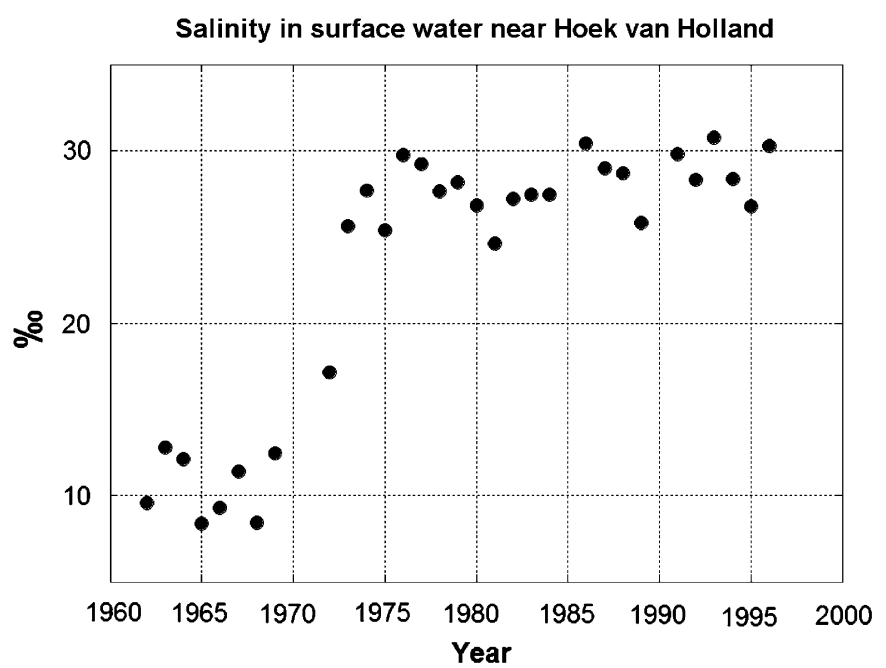

Fig. 10. The evolution of the annually averaged salinity along the beach at Hoek van Holland (northwards of the northern pier), 1962-1997.

sharp rise around this time, apparently by the more efficient shielding off of fresh water by the extended pier. A plausible explanation for the positive jump of the Hoek van Holland sea level might be, therefore, that in the direct vicinity of TG Hoek van Holland, situated inside the mouth of the Nieuwe Waterweg, the salinity has been raised due to the extension of the northern pier. The abrupt increase of salinity from $8-18 \%$ to $25-33 \%$ coincides surprisingly well with the time of shifting suggested by the GLR detector above. A precise modelling of the impact of hydraulic conditions on the sea level near Hoek van Holland is beyond the scope of this study. Nevertheless, it is notable that the jump is indicated by the GLR test exactly in the period of rapid modifications of the Nieuwe Waterweg and construction of the Maasvlakte. 
Table 2

The comparison of sea level trends.

\begin{tabular}{llll}
\hline Station & $\begin{array}{l}\text { SLH trend mm/yr } \\
\text { (De Ronde, 1983) } \\
1900-1980\end{array}$ & $\begin{array}{l}\text { SLH trend mm/yr } \\
1940-2002\end{array}$ & $\begin{array}{l}\text { SLH corrected } \\
\text { trend mm/yr } \\
1940-2002\end{array}$ \\
\hline IJmuiden & 2.1 & 1.94 & 1.94 \\
Hoek v.H. & 1.9 & 2.68 & 2.09 \\
Maassluis & - & 2.12 & 2.12 \\
Vlissingen & 2.2 & 1.68 & 2.08 \\
\hline
\end{tabular}

The Vlissingen TG station is situated in the Westerschelde. The Westerschelde is the seaward, marine part of the tide-dominated Schelde estuary. Land reclamation, damming and dredging influenced the natural evolution of the estuary during the last centuries. The abrupt decrease in sea level of $17 \mathrm{~mm}$ at the Vlissingen TG might be attributed to deepening of the channel system by extensive dredging around this time (Wang et al., 2002), or changes in the morphological system of the Westerschelde (Hollebrandse, 2005). More likely, however, seems the presence of some untractable error in the maintenance of the TG or the processing of the data. The still available documentation on comparisons of the TG with staff readings do not reveal an adjustment of the TG around this time, however.

\section{The consistency of the corrected records}

Now we revaluate the sea level trends by correcting the tidal records at Hoek van Holland and Vlissingen for the detected shifts (Table 1). Table 2 summarizes the trends in the original and corrected data and compare them to the estimates of De Ronde (1983) for the earlier period 1900-1980. The estimates of the sea level rise from corrected tidal records are much more coherent: nearly the same trend of $2.1 \pm 0.1 \mathrm{~mm} / \mathrm{yr}$ is observed at Vlissingen, Hoek van Holland and Maassluis and a slightly lower value of $1.9 \pm 0.1 \mathrm{~mm} / \mathrm{yr}$ at IJmuiden. The new estimates agree well with those obtained by De Ronde (1983) and van Malde (1992). Over earlier time intervals and concord as well with the general decreasing of sea level trends from the Southern to Northern part of the Dutch coast (De Ronde, 1983).

In order to compare the sea level trends with the recent IPCC estimates, the land movement near TGs due to the post-glacial rebound should be taken into account. The model of Lambeck et al. (1998) adjusted to the Holocene observations along the Dutch, German and Belgian coasts predicts a land subsidence induced by the post-glacial rebound of about $0.1 \mathrm{~mm} / \mathrm{yr}$ (Kooi et al., 1998) at all four TGs considered in this study. The recent models VM2 and VM4 of Peltier (2004) predict the sea level rise of about $0.16-0.18 \mathrm{~mm} / \mathrm{yr}$ at IJmuiden, the sea level rise not larger than $0.05 \mathrm{~mm} / \mathrm{yr}$ at Hoek van Holland and Maassluis and the sea level subsidence of $0.06-0.10 \mathrm{~mm} / \mathrm{yr}$ at Vlissingen. Subtracting them from trends of corrected records in Table 2 leads to rates of sea level rise comprised between $2.0 \mathrm{~mm} / \mathrm{yr}$ at Vlissingen to $2.17 \mathrm{~mm} /$ $\mathrm{yr}$ at Maassluis. These estimates are just above the IPCC estimate of $1.7 \mathrm{~mm} / \mathrm{yr}$ for the average rate of sea level rise during the 20th century.

\section{Conclusions}

We have analysed whether the inconsistency between the rate of the sea level rise at IJmuiden, Hoek van Holland, Maassluis and Vlissingen can be due to an abrupt shift of mean level in the original tidal gauge records. Decomposing the sea level observa- tions in EOFs has allowed an efficient filtering of global and regional scale variabilities. A shift detector based on the GLR test has been proved to be effective for searching an abrupt shift whose amplitude can be as small as $70 \%$ of the standard deviation of tidal records. The numerical experiments with different models of the correlated noise have shown that the detector is also robust and thus suitable for systematic inspection of sea level observations.

The statistical testing (at the significance level 5\%) of a shift's presence in the tidal records has led to the following conclusions:

(1) A shift in the mean of $25 \mathrm{~mm}$ at Hoek van Holland during $1972-1973$ is statistically significant with the probability of detection $93 \%$.

(2) A shift of mean of the amplitude $17 \mathrm{~mm}$ at Vlissingen during 1973-1976 is statistically significant, the probability of detection being $97 \%$.

The trends in the corrected TG records at Hoek van Holland and Vlissingen are equal to $2.1 \pm 0.1 \mathrm{~mm} / \mathrm{yr}$ as that in Maassluis record and is a little larger than the trend of $1.9 \pm 0.1 \mathrm{~mm} / \mathrm{yr}$ observed at IJmuiden.

It should be stressed that the technique employed in this study is especially effective for analysing the consistency of sea level measurements within a TG network. In this case, filtering of global sea variabilities based EOF decomposition increases the signal/ noise ratio of sea level data and enhances the efficiency of the GLR-based shift detector. Since an unknown step-like jump can crucially change an estimation of the sea level rise, the proposed detector should be included in any analysis of the long-term sea level variations.

\section{Appendix A. Impact of a shift in mean on sea level trend}

Consider a sequence of $M$ sea level heights, $\eta_{i}$, with no abrupt shifts or gaps inside it. Let $b_{0}$ represent the slope of a regression line fitted to the observed sea levels by the least squares method. Suppose, now, that this sea level record is offset at a point $t_{s}$ from its beginning by a shift of amplitude $\Delta s$. Let $b_{1}$ stand for the slope of the regression line adjusted to the offset record. Then the perturbation of the regression line slope induced by the shift is given by van Onselen (2000)

$\Delta b=b_{1}-b_{0}=6 \Delta \mathbf{s} \frac{t_{s}\left(t_{s}-M\right)}{M\left(M^{2}-1\right)}$

\section{References}

Barbosa, S.M., Fernandes, M.J., Silva, M.E., 2006. Long-range dependence in North Atlantic sea level. Physica A: Statistical Mechanics and its Applications 372 (2), 725-731.

Basseville, M., Nikiforov, I., 1993. Detection of Abrupt Changes: Theory and Application. Information and System Science Series. Prentice-Hall, Englewood Cliffs.

Berger, W.H., Labeyrie, L.D., 1987. Abrupt Climatic Change Evidence and Implications. NATO Advanced Research Workshop on Abrupt Climatic Change (S Hugues de Biviers, France, 1985), vol. 21 (1), Springer, Berlin.

Brownlee, K.A., 1965. Statistical Theory and Methodology in Science and Engineering. A Wiley Publication in Applied Statistics, second ed. Wiley, New York.

Cazenave, A., Nerem, R., 2004. Present-day sea level change: observations and causes. Reviews of Geophysics 42, 120.

Church, J.A., White, N.J., Coleman, R., Lambeck, K., Mitrovica, J.X., 2004. Estimates of the regional distribution of sea level rise over the 1950-2000 period. Journal of Climate 17 (13), 2609-2625.

Day, S.J., Watts, P., Grilli, S.T., Kirby, J.T., 2005. Mechanical models of the 1975 Kalapana, Hawaii earthquake and tsunami. Marine Geology 215 (1-2), 59-92 Special Issue. 
De Ronde, J.G., 1983. Changes of relative sea-level and of mean tidal amplitude along the Dutch coast. In: Ritsema, A.R., Guerpinas, A. (Eds.), Seismicity and Seismic Risk in the Offshore North Sea Area. NATO Advanced Research Workshop. Reidel, Dordrecht, pp. 131-141.

Douglas, B.C., 1997. Global sea rise: a redetermination. Surveys in Geophysics 18 (2-3), 279-292.

Douglas, B.C., 2001. Sea level change in the Era of the recording tide gauges. In: Douglas, B.C., et al. (Eds.), Sea Level Rise: History and Consequences. Academic Press, New York.

Efron, B.E., Tibshirani, R.J., 1993. An introduction to the bootstrap, Monographs on Statistics and Applied Probability, vol. 57. Chapman \& Hall, New York, 436pp (republished by CRC Press, 1998).

Ekman, M., 1999. Climate changes detected through the world's longest sea level series. Global and Planetary Change 21 (4), 215-224.

Emery, K.O., Aubrey, D.G., 1991. Sea Levels, Land Levels, and Tide Gauges, first ed. Springer, New York.

Fujii, Y., Nakane, K., 1997. Reevaluation of anomalous vertical crustal movement associated with the 1964 Niigata, Japan, earthquake. Pure and Applied Geophysics 149 (1), 115-127.

Gornitz, V., 1995. Monitoring sea level changes. Climatic Change 31 (2-4), $515-544$.

Gornitz, V., 2001. Impoundment, groundwater mining, and other hydrologic transformations: impacts on global sea level rise. In: Douglas, B.C., et al. (Eds.) Sea Level Rise: History and Consequences. Academic Press, New York, pp. 97-119.

Gough, W.A., Robinson, C.A., 2000. Sea-level variation in Hudson Bay, Canada, from tide-gauge data. Arctic, Antarctic, and Alpine Research 32 (3), 331-335.

Gough, W.A., Robinson, C.A., Hosseinian, R., 2005. The influence of James Bay river discharge on Churchill, Manitoba sea level. Polar Geography 29 (3), 213-223.

Holgate, S.J., Woodworth, P.L., 2004. Evidence for enhanced coastal sea level rise during the 1990s. Geophysical Research Letters 31 (7), 1-4.

Hollebrandse, F.A.P., 2005. Temporal development of the tidal range in the southern North Sea. Ph.D. Thesis, Faculty of Civil Engineering and Geosciences, Hydraulic Engineering, TU Delft.

Hurst, H.E., 1957. A suggested statistical model of some time series which occur in nature. Nature 180, 494

IPCC, 2007. IPCC Fourth Assessment Report: Climate Change 2007_Working Group II: Impacts, Adaptation and Vulnerability. Intergovernmental Panel on Climate Change, United Nations, Geneva.

Jelgersma, S., 1992. Vulnerability of the coastal lowlands of the Netherlands to a future sea-level rise. In: Tooley, M.J., Jelgersma, S. (Eds.), Impacts of Sea-level Rise on European Coastal Lowlands, vol. 27. The Institute of British Geographers Special Publications Series, pp. 94-123.

Jevrejeva, S., Grinsted, A., Moore, J.C., Holgate, S., 2006. Nonlinear trends and multiyear cycles in sea level records. Journal of Geophysical Research C-Oceans 11 (9).

Kay, S.M., 1998. Fundamentals of Statistical Signal Processing. Detection Theory, vol. 2. Prentice-Hall, Englewood Cliffs, NJ.

Kooi, H., Johnstonn, P., Lambeck, K., Smither, C., Molendijk, R., 1998. Geologica causes of recent $(100 \mathrm{yr})$ vertical land movement in the Netherlands. Tectonophysics 299, 297-316.

Lambeck, K., Smither, C., Johnston, P., 1998. Sea-level change, glacial rebound and mantle viscosity for Northern Europe. Geophysical Journal International 134 102-144.
Langenberg, H., Pfizenmayer, A., Von Storch, H., Sundermann, J., 1999. Storm-related sea level variations along the North Sea coast: natural variability and anthropogenic change. Continental Shelf Research 19 (6), 821-842.

Mandelbrot, B.B., Van Ness, J.R., 1968. Fractional Brownian motions, fractional noises and applications. SIAM Review 10 (422).

Marcos, M., Gomis, D., Monserrat, S., Alvarez-Fanjul, E., Perez, B., Garcia-Lafuente, J., 2005. Consistency of long sea-level time series in the northern coast of Spain. Journal of Geophysical Research C-Oceans 110 (3), 1-13.

Papoulis, A., 1991. Probability, Random Variables and Stochastic Processes, third ed. McGraw-Hill, New York, 667pp.

Peltier, W.R., 2004. Global glacial isostasy and the surface of the ice-age earth: the ICE-5G(VM2) model and GRACE. Annual Review of Earth and Planetary Sciences 32, 111-149.

Preisendorfer, R.W., 1988. Principal Component Analysis in Meteorology and Oceanography. Elsevier, New York.

Rodionov, S.N., 2005. A brief overview of the regime shift detection methods. In: Velikova, V., Chipev, N. (Eds.), Large-Scale Disturbances (Regime Shifts) and Recovery in Aquatic Ecosystems: Challenges for Management Toward Sustainability.

Rodolfo, K.S., Siringan, F.P., 2006. Global sea-level rise is recognised, but flooding from anthropogenic land subsidence is ignored around northern Manila Bay, Philippines. Disasters 30 (1), 118-139.

Seno, T., 2004. Intermediate-term precursors of great subduction zone earthquakes: an application for predicting the Tokai earthquake. Earth, Planets and Space 56 (7), 621-633.

Tawn, J.A., Dixon, M.J., Woodworth, P.L., 1994. Trends in sea-levels. Statistics for the Environment 2: Water Related Issues, pp. 147-181.

van Malde, J., 1992. Relative rise of mean sea-levels in the Netherlands in recent times. In: Tooley, M.J., Jelgersma, S. (Eds.), Impacts of Sea-level Rise on European Coastal Lowlands, vol. 27. The institute of British Geographers Special Publications Series, pp. 36-55.

van Onselen, K.I., 2000. The influence of data quality on the detectability of sealevel height variations. Ph.D. Thesis, NCG Publications on Geodesy, vol. 49, TU Delft.

von Storch, H., Zweirs, F.W., 1999. Statistical Analysis in Climate Research, first ed. Cambridge University Press, Cambridge.

Woodworth, P., 1987. Trends in UK mean sea level. Marine Geodesy 11, 57-87.

Woodworth, P., 1991. The permanent service for mean sea level and the global sea level observing system. Journal of Coastal Research 7, 671-699.

Woodworth, P.L., Tsimplis, M.N., Flather, R.A., Shennan, I., 1999. A review of the trends observed in British Isles mean sea level data measured by tide gauges. Geophysical Journal International 135, 651-670.

Woodworth, P.L., Player, R., 2003. The permanent service for mean sea level: an update to the 21st century. Journal of Coastal Research 19 (2), 287-295.

Woodworth, P.L., 2006. Some important issues to do with long-term sea level change. Philosophical Transactions: Mathematical, Physical and Engineering Sciences, Series A 19 (2), 287-295.

Wang, Z.B., Jeuken, M.C., Gerritsen, H., de Vriend, H.J., Kornman, B.A., 2002. Morphology and asymmetry of the vertical tide in the Westerschelde estuary. Continental Shelf Research 22 (17), 2599-2609.

Zweirs, F.W., von Storch, H., 1995. Taking serial correlation into account in tests of the mean. Journal of Climate 8, 336-351. 